\title{
REVISIÓN
}

\section{Natural antioxidants in functional foods: from food safety to health benefits}

\author{
By Alfonso Valenzuela B*, Julio Sanhueza and Susana Nieto
}

Laboratorio de Lípidos y Antioxidantes. Instituto de Nutrición y Tecnología de Alimentos (INTA), Universidad de Chile, Casilla 138-11, Santiago, Chile.

E-mail: avalenzu@uec.inta.uchile.cl

\section{RESUMEN}

Antioxidantes naturales en alimentos funcionales: de la seguridad alimentaria a los beneficios en la salud.

El oxígeno es un metabolito esencial para la vida. Sin embargo puede ser altamente dañino para el organismo y para los alimentos que consumimos si su actividad no es controlada. Uno de los efectos mas deteriorativos del oxígeno es la oxidación de los lípidos o rancidez oxidativa. Este es un proceso que en los alimentos iniciado por las llamadas especies reactivas del oxigmentos es ine no (ROS), las que prganismos vivos como consecuencia de la actividad metabólica de estos, con efectos graves para estos organismos. Ciertos procesos metabólicos requieren de la participación de los ROS, por lo cual el control de la formación y destrucción de los ROS es de gran importancia. El estrés oxidativo se define como un desequilibrio en el balance entre la formación y destrucción de los ROS, y es en este proceso donde los antioxidantes, sintéticos o naturales, tienen una función protectora importante. Los antioxidantes sintéticos son ampliamente utilizados en la industria de los alimentos. Sin embargo existe preocupación respecto de su seguridad, lo cual ha dirigido el interés hacia los antioxidantes naturales ya que estos se consideran mas seguros. Antioxidantes naturales como los tocoferoles, el ácido ascórbico, el extracto de rosemary, el licopeno y algunos flavonoides, están en la actualidad disponibles para ser adicionados a los alimentos en reemplazo de los antioxidantes sintéticos. Los antioxidantes naturales pueden, además, dantes sintéticos. Los antioxidantes naturales pueden, además, reforzar la actividad de los sistemas antioxidantes endógenos aportando una protección extra para el estres oxidativo. Los alimentos adicionados de antioxidantes naturales pueden ser considerados como alimentos funcionales ya que proveerían de una

PALABRAS-CLAVE: Alimentos funcionales - Antioxidantes naturales - Antioxidantes sintéticos - Estrés oxidativo - Oxida ción de lípidos - Rancidez oxidativa.

\section{SUMMARY}

Natural antioxidants in functional foods: from food safety to health benefits.

Oxygen is essential for metabolism but it may be highly damaging for both organisms and foods unless properly controlled. Among uncontrolled detrimental processes lipid oxidation (or oxidative rancidity) is one of the most relevant. oxidation (or oxidative rancidity) is one of the most relevant.
Oxidative rancidity of foods is initiated by reactive oxygen species Oxidative rancidity of foods is initiated by reactive oxygen species
(ROS). ROS are also formed in living organisms as consequence of metabolic activity with potentially sided effects, though a certain physiological level of ROS is crucial for the regulation of cell functions. Oxidative stress is defined as a disturbance in the pro-oxidant/anti-oxidant balance and antioxidants of synthetic or natural origin may have an important role in the maintenance of this balance. Synthetic antioxidants are widely used in the food industry, however concerns about their safety have changed the interest to natural antioxidants which are presumed to be safe. Natural antioxidants such as tocopherols, ascorbic acid, resemary Natural antioxidants such as tocopherols, ascorbic acid, rosemary extracts, lycopene and some flavonoids are now available to be added to foods in replacement of synthetic products. These antioxidants may reinforce the activity of the endogenous antioxidant systems providing extra protection against oxidative stress. Food preserved with added natural antioxidants can be considered as functional foods because these products can provide better health conditions to consumer.

KEY-WORDS: Functional foods - Lipid oxidation - Natural antioxidants - Oxidative rancidity - Oxidative stress - Synthetic antioxidants.

\section{INTRODUCTION}

Food and oxygen, the two fundamentals of human and animal life, are actually involved in intricately conflicting interactions. The deterioration of food with time, a process that results from its largely biological nature, is inevitable and from a chemical view, oxygen is directly involved in food deterioration. On the other hand, despite the fact that we depend on oxygen for biological oxidation as a source of energy substrates for survival and activity, the action of oxygen at the cellular level may really be two-sided. Oxygen is essential for metabolism but in some circumstances may be highly damaging unless properly controlled. A large body of scientific evidences has accumulated describing the physiological effects of uncontrolled oxidation. These effects range from inefficient nutrient metabolism to direct and harmful effects on cellular structure and function (Halliwell, 1999). Among these uncontrolled detrimental processes for both foods and cells, lipid oxidation is probably one of the most relevant (Benzie, 1996).

\section{LIPID OXIDATION: A MECHANISM FOR FOOD DETERIORATION}

Lipid oxidation is one of the main causes of food deterioration. The development of this process generally referred to as oxidative rancidity, is often the decisive factor in determining the useful storage 
life of food products, even when their fat content is as low as $0.5 \%$ or $1 \%$. Oxidative rancidity can occur when unsaturated portions of fatty acid esters (triglycerides or phospholipids) react with molecular oxygen to form peroxides, hydroperoxides and carbonyl compounds (Benzie, 1996). The hydroperoxides split into smaller short-chain organic compounds such as aldehydes, ketones, alcohols, and acids that cause the off odor and flavor characteristics of the oxidized fats and oils (Valenzuela \& Nieto, 1996). Oxidative rancidity affects not only the fatty acid component of foods, but also the cholesterol content of foods from animal origin. Cholesterol, like unsaturated fatty acids, may be oxidized to form oxysterols, which are also as toxic as fatty acid-derived hydroperoxides (Smith \& Johnson, 1989). Consumption of oxysterol-containing foods may be potentially harmful to cellular physiology (Morel \& Lin, 1996). Oxidative rancidity also brings about undesirable changes in color, aroma, and other quality aspects of affected foods (Robey \& Shermer, 1994). The nutritional value of a product is impaired and even toxicity may be induced, and many food-processing practices tend to exacerbate these unwanted changes.

Oxidative rancidity is initiated by the so called 'reactive oxygen species' (ROS) (Evans \& Halliwell, 2001). This term combines various free radicals which include oxygen-centered free radicals (activated oxygen-containing molecules) but also non-radical derivatives of oxygen. Free radicals contain one or more unpaired electrons and are capable of independent existence. Free radicals can be formed by three ways: the loss of a single electron from a non-radical molecule; the addition of a single electron to a non-radical molecule; or the homolytic cleavage of the covalent bond of a non-radical molecule, so that each fragment retains one of the electrons (Cheeseman \& Slater, 1993). This electron imbalance causes the radical to search for another electron to form a complete pair. ROS include the hydroxyl free radical $(\bullet \mathrm{OH})$, the superoxide free-radical $\left(\mathrm{O}_{2}{ }^{\circ}\right)$, the nitric oxide free-radical $(\mathrm{NO} \bullet)$, and the non-radicals hydrogen peroxide $\left(\mathrm{H}_{2} \mathrm{O}_{2}\right)$ and singlet oxygen (Sies, 1993).

The hydroxyl free radical is one of the most reactive of the ROS. Exposure of living organisms to ionizing radiation causes fission of $\mathrm{O}-\mathrm{H}$ bonds in water to give $\mathrm{H} \bullet$ and $\bullet \mathrm{OH}$, (Halliwell, 1994). Hydroxyl free radical reacts at a diffusion-controlled rate with almost all molecules in living cells. Hence, when $\bullet \mathrm{OH}$ is formed in vivo, it damages whatever it is near, as - $\mathrm{OH}$ can not migrate any significant distance within cell. Many, if not most, of the harmful effects of excess exposure to ionizing radiation upon living organism are thought to be initiated by attack of $\bullet \mathrm{OH}$ upon proteins, carbohydrates, nucleic acid, and lipids. Superoxide free radical is the major one-electron reduction product of oxygen produced in biological systems (Babior \& Woodman, 1990). It is produced by phagocytic cells (neutrophils, macrophages, eosinophils) and helps them to inactivate viruses and bacteria. Superoxide free radical produced by such cells is often though to be involved in intercellular signaling and growth regulation. Several reports indicate that vascular endothelial cells generate $\mathrm{O}_{2}$.' after an insult, such as occurs during an ischemia-reperfusion vascular accident. Nitric oxide is a type of free radical produced metabolically in living organisms (Diplock et al., 1998). It is synthesized from the amino acid L-arginine by vascular endothelial cells, phagocytes, certain cells in the brain, and many other cell types. Whereas $\bullet \mathrm{OH}$ is virtually always harmful, $\mathrm{NO} \bullet$ is a vasodilator agent and possibly an important neurotransmitter (Bredt, 1999). It is also involved in the killing of parasites by macrophages in some mammalian species. Hydrogen peroxide resembles water in its molecular structure and it easily diffuses within and between cells. Intracellularly it is formed from the reaction between two superoxide free radicals through a dismutation process (the simultaneous oxido-reduction reaction between two superoxide radicals). Hydrogen peroxide by itself is a poorly reactive molecule, but it can be toxic through its reaction with $\mathrm{O}_{2}$. to form hydroxyl free radicals (Haber-Weiss reaction). Several metal ions are remarkably good promoters of free radical reactions in vivo. Hydrogen peroxide can react with ferrous iron or copper or produce hydroxyl free radicals by the Fenton reaction (Beckman \& Ames, 1998). Because transition metal ions can be responsible for ROS production, these ions are normally safely sequestered with proteins such as transferrin, lactoferrin, ceruloplasmin, and albumin (Sardesai, 1995). Hydrogen peroxide is also produced by the action of several oxidative enzymes in vivo, including amino acid oxidases, and the enzyme xanthine oxidase (Halliwell, 1994). This enzyme catalyzes the oxidation of hypoxanthine to xanthine, and of xanthine to uric acid. Levels of the enzyme often increases when tissues are subjected to insult, such as trauma or deprivation of oxygen, leading to the generation of higher amounts of $\mathrm{H}_{2} \mathrm{O}_{2}$ (Lachance et al., 2001) Hydrogen peroxide is also involved in the oxidative stress which characterizes isquemia-reperfussion vascular accidents (Oldman \& Bowen, 1998). Figure 1 summarizes the main reactive oxygen species.

A certain physiological level of ROS is crucial for the regulation of cell functions such as intracellular signaling, transcription activation, cell proliferation, inflammation, and apoptosis (Herrera et al., 2001). The reduction-oxidation (redox) state of the cell is a consequence of the balance between levels of ROS and endogenous protective systems (see below). Oxidizing equivalents in excess of the cell-buffering 


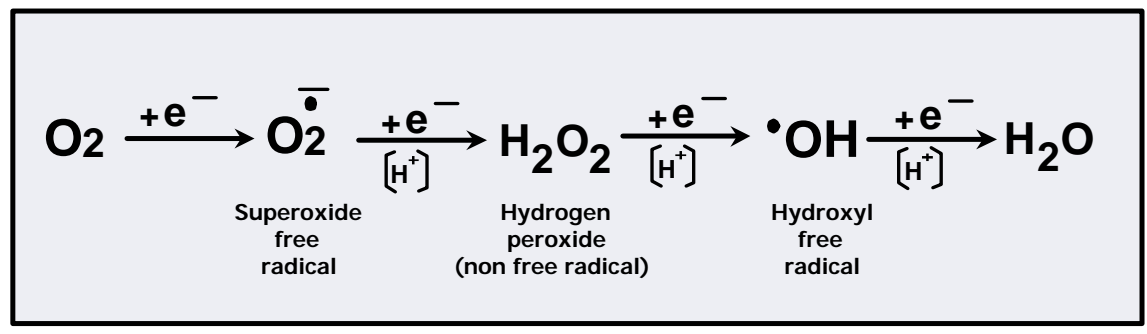

Figure 1

Reactive oxygen species (Ros)

capacity results in potential cytotoxic damage (Allen \& Tresini, 2000).

\section{PREVENTING OXIDATIVE RANCIDITY: THE ROLE OF ANTIOXIDANTS}

Oxidative rancidity prevention is of economic and health importance, therefore great efforts are expended in controlling the process. Antioxidants are organic molecules of either synthetic or natural origin, which can avoid or delay the progress of oxidative rancidity (Dorko, 1994). Their ability to do this is based mainly on their phenol-derived structure. Antioxidants work by donating hydrogen to the lipid free radical to reform the fat molecule or by donating one hydrogen to a peroxide free radical to form a hydroperoxide and a stable antioxidant free radical (Valenzuela \& Nieto, 1996). Hundreds of synthetic and natural antioxidants have been evaluated for antioxidant efficacy. Of the synthetic products only five have found widespread use: Butylated hydroxyanisole (BHA), butylated hydroxytoluene (BHT), propyl gallate (PG), tertiarybutyl hydroquinone (TBHQ), and ethoxyquin (EQ). The first four are approved for human consumption, although with increasing restrictions. Ethoxyquin is only accepted for animal feeding, but also with recent restrictions for application in the pet food industry. Over the last two decades, interest in using antioxidants of natural origin in food has increased dramatically. Many attempts have been made to replace synthetic antioxidants by natural products in the stabilization of fats against oxidative rancidity (Aruoma, 1997). The emphasis given to natural antioxidants results from concerns over the toxicity of some synthetic antioxidants, such as BHA, BHT, and EQ (Thompson \& Moldeus, 1988; Dzanis, 1991), and from the search findings which point to a relationship between bioactive dietary ingredients, like natural antioxidants, and their protection of cells from oxidative damage in the human body.

Natural antioxidants, which are present in variable amounts in vegetables such as fruits, leaves, flowers, roots, grains and seeds, have gained prominence as alternatives to synthetic antioxidants. Much interest has developed in recent years in naturally occurring antioxidants because of the worldwide trend toward the usage of natural additives in foods. Natural antioxidant substances are presumed to be safe since they occur in plant foods, and are seen as more desirable than their synthetic counterparts. Plant extracts that have been suggested to have antioxidant activity include rosemary, sage, cocoa shells, oats, tea, olive, garlic, ginger, red onion skin, grapes, apple cuticle, clove, oregano, and thyme (Aruoma, 1997). However, research interest in the properties and occurrence of natural antioxidants centers mainly upon vitamin $E$, vitamin $C$ (ascorbic and dehydroascorbic acid), some carotenoids, phenolic acids, some spice extracts and various flavonoids (Shahidi, 2000).

Vitamin $E$ is the most important dietary component contributing to natural antioxidant defenses in tissues (Meydani, 1995). It is a collective term comprising eight compounds synthesized by plants. These fall in two classes, the tocopherols having a saturated side chain, and the tocotrienols having an unsaturated side chain. Within each class, there are four structural homologues (not isomers), designated alpha, beta, gamma, and delta, which vary in the number of methyl groups on the chroman ring (Bieri, 1984). Of these eight compounds only four have nutritional significance; alpha-, beta-, and gamma-tocopherol and alpha-tocotrienol, and only two have antioxidant action- alpha- and gamma-tocopherol (Meydani, 1995). These tocopherols are responsible for the inherent stability of vegetable oils. At the cellular level tocopherols are mainly distributed in membrane structures and plasma lipoproteins due their highly lipophilic characteristics (Jessup et al., 1990). Vitamin $E$ deficiency is associated with a range of specific diseases including immunoincompetence, impairment of lipid metabolism, fertility problems and increased susceptibility to common and specific diseases (Machlin, 1991). Vitamin E can not be synthesized in the human and adequate nutritional status relies upon adherence to a well balanced diet (Thurman \& Mooradian, 1997). The major vitamin E 
sources in the diet are vegetable oils (wheat, soybean, sunflower and corn) and some other plant-derived foods. It has been suggested that by enhancing vitamin $E$ intake with fortification of foods or dietary supplements it may be possible to reduce the risk of many common, yet disabling, human diseases (Diplock, 1997; Azzi et al., 1998).

Vitamin $C$ is referred to as L-ascorbic acid and its two-electron reduction product dehydro-L-ascorbic acid. It is considered to be one of the most powerful, least toxic, water-soluble natural antioxidant (Weber et al., 1996). Due its hydrophilic properties, ascorbic acid can function as a free radical scavenger in an aqueous environment. It is found in high concentrations in many tissues and is considered the major defense mechanism in blood plasma. Ascorbic acid (or ascorbate) can efficiently scavenge ROS such as $\mathrm{O}_{2} \bullet$ and $\bullet \mathrm{OH}$ free radicals. On interaction with $\mathrm{ROS}$ it is oxidized to dehydro-ascorbate via intermediate ascorbyl free radical. Dehydro-ascorbate is recycled back to ascorbic acid by the enzyme dehydroascorbate reductase. Thus dehydro-ascorbate is found in only very low levels compared with ascorbate. The major sources of ascorbate in the diet are green vegetables and fruits, especially citrus fruits. There is evidence that vitamin $C$ can act synergistically with vitamin $\mathrm{E}$, both in vivo and in vitro systems (Niki et al., 1982). Ascorbic acid is capable of regenerating tocopherols from the tocopheroxyl free radical which is formed on inhibition of lipid peroxidation by vitamin $\mathrm{E}$. This process would allow for the transport of a radical load from a lipophilic compartment, such as the cell membrane, to an aqueous compartment where it is taken care by the cytoplasmatic enzyme defense system (Diplock et al., 1998). It should be noted however, that ascorbate might also act as a pro-oxidant in vivo. In the presence of free transition metal ions $\left(\mathrm{Fe}^{2+}\right.$ and $\left.\mathrm{Cu}^{2+}\right)$ and ascorbate, the hydroxyl free radical can be generated and initiation of lipid peroxidation may occur (Carr \& Frei, 1999). However, the amounts of free transition metals in vivo are very small because they are efficiently bound to proteins (intracellular and extracellular binding proteins), therefore it is believed that in physiological conditions ascorbic acid performs only antioxidant functions. The human gastrointestinal track readily absorbs both vitamins $\mathrm{C}$ and $E$, and the human body has evolved mechanisms for taking up ascorbate and transporting it into the cell. Vitamin $\mathrm{C}$ in addition to its antioxidant capacity, has additional well-established biological functions including cofactor activity for several important enzymes (Levine et al, 1996).

Extracts of herbs of the Laminaceae family, such as rosemary and sage, have played an important role in natural antioxidant research (Madsen \& Bertelsen, 1995). The hexane extracts of the leaves of the evergreen shrub rosemary (Rosmarinus officinalis $L$ ) contain four effective antioxidants: carnosol, rosmanol, isorosmanol, and rosmary-diphenol (Chen et al., 1992). These four compounds when processed, are odorless and tasteless diterpenolactones and among these lactones, rosmary-diphenol and rosmanol show antioxidant activity stronger than $\mathrm{BHA}$ and $\mathrm{BHT}$ but weaker than TBHQ (Richheimer et al., 1996). Rosemary extract is effective in stabilizing frying oils and has very good thermal resistance (Valenzuela et al., 2002 ${ }^{\mathrm{a}}$ ), and is commercially available for use as a natural antioxidant in the United States and Europe, where rosemary products reportedly represent about $40 \%-50 \%$ of the food-grade natural antioxidant market. The investigation of the antioxidative effects of spices, such as rosemary, is limited because addition of these spices to foods may produce modification in aroma. In many commercial products attempts are made to extract the component(s) responsible for the antioxidative effect and concomitantly to reduce the co-extraction of the essential oil that give to the spice its aroma.

Flavonoids constitute a large group of naturally occurring plant products that are widely distributed in the vegetable kingdom. They are widespread in nature, occurring in all plant families, and are found in considerable amounts in fruits, vegetables, grains, tea, coffee, cocoa, beer, and red wine (Skibola \& Smith, 2000). Flavonoids belong structurally to a large chemical group known as polyphenols which range from simple phenolic molecules to polymeric structures with molecular weights in excess of 30,000 Daltons. All of them are structurally derived from the parent compound flavone (2-phenylchromone) and are characterized by two benzene rings joined by a C3 structure which is condensed as a six-member ring that changes with the nature of the flavonoid (Havsteen, 1983). The major flavonoid classes include flavonols, flavones, flavanones, flavanols (catechins), anthocyanidins, isoflavones, dihydroflavonols, and chalcones (Cook \& Samman, 1996). For centuries a number of different therapeutic and curative properties have been ascribed to flavonoids and many of them have been incorporated to the popular folk medicine. Several grams of flavonoids are consumed daily and most of them exhibit antioxidant activity in both aqueous-and lipid-phase assay systems (Pietta, 2000), and their free radical scavenger activity can largely be predicted on the basis of their chemical structure (Bravo, 1998). Antioxidant activity for a number of different flavonoids has been described in different oxidation models. Flavonoids, such as quercetin, catechin, morin, and rutin show potent antioxidant action when assayed using metal-induced fish oil oxidation (Nieto et al., 1993) or thermally-induced cholesterol oxidation (Valenzuela et al., 2002). Some flavonoids also show strong metal-chelating action which favor its antioxidant 
behavior (Cook \& Samman, 1996). The antioxidant activity of many flavonoids sometime surpasses the effectiveness of vitamin $C$ and vitamin $E$ in aqueousand lipid-phase models, respectively (Oldman \& Bowen, 1998). Flavonoids have become widely accepted as physiological antioxidants with the potential to protect against the many degenerative diseases linked to ROS-related tissue damage (Dreosti, 2000).

Lycopene is another natural antioxidant with potential application in the food industry (Rao \& Agarwal, 1999). It is an non-cyclic isomer of beta-carotene that contains 11 conjugated double bonds linearly arranged and is synthesized by plants and microorganisms but not by animals. The molecule has no vitamin A activity because it lacks the beta-ionone ring of alpha- and beta-carotene. Carotenoids are considered antioxidants because they have the ability to quench ROS and lycopene is one of the most potent antioxidants among dietary carotenoids. Its all-trans-isomeric form may efficiently quench singlet oxygen and trap peroxy radicals (Burton \& Ingold, 1984). Lycopene is readily absorbed from different food sources, particularly from tomatoes and tomato-based products (Clinton, 1998). Tomato juice, ketchup, tomato soup, tomato-based pizza and spaghetti sauce are the major contributors of lycopene to the diet. Not all red fruits and vegetables contain lycopene, and other food sources, besides raw tomatoes, include watermelon, pink grapefruit, papaya and pink guava. Lycopene from tomato products that have been cooked is absorbed more readily than that from raw tomatoes. The carotenoid distributes to different tissues and maintains its antioxidant properties in the body (Stahl \& Sies, 1996). It has been suggested that lycopene has anti-cell-proliferative, anticarcinogenic, and antiatherogenic activities (Gerster, 1997). Epidemiological and experimental studies have provided evidence in support a protective role of lycopene in heart disease and cancer, and recent meta-analysis of the epidemiological literature indicated that higher intake of lycopene is related to reduced risk of several human cancers (Rao \& Agarwal, 2000). Although antioxidant properties of lycopene are thought to be responsible primarily for its biological effects, other mechanisms for its protective action have been suggested (Clinton, 1998). Interest in the role that lycopene may play in health and disease and as a potential natural food antioxidant has grown enormously in the last years and is now a common topic for discussion among scientists, dietitians, and food technologists.

\section{FROM OXIDATIVE RANCIDITY TO OXIDATIVE STRESS}

The cellular metabolism of oxygen in aerobic organisms continuously produces small amounts of
ROS and large increases in the amount of these reactive species lead to 'oxidative stress', which is defined as a disturbance in the pro-oxidantantioxidant balance in favor of the pro-oxidants leading to potential damage. Oxidative stress may be influenced by a number of different factors, such as genetics, age, nutritional status, environment, drug consumption, medication, etc (Lachance et al., 2001). Under normal circumstances, the major source of ROS produced in the body occurs from the leakage of electrons from the mitochondrial and microsomal electron transport chains (Halliwell, 1994). However, phagocytic cells, and endogenous enzyme systems, such as nicotinamide adenine dinucleotide phosphate oxidase, xanthine oxidase, monoamine oxidase, and the microsomal cytochrome P-450 oxidase system, may be also important sources of ROS (Sardesai, 1995; Lachance et al., 2001). All aerobically respiring cells reduce molecular oxygen to create ROS, mainly O2 - Electrons normally pass down a non-radical generating, cytochrome-catalyzed reduction of oxygen to water during mitochondrial oxidative phosphorylation (ATP production). Superoxide is formed when electrons do not complete the cascade (Schiller et al., 1993). Similarly, during the metabolic activation of xenobiotics, the leakage of electrons of cytochrome P-450 in liver endoplasmatic reticular membranes (microsomes) results in the formation of $\mathrm{O}_{2} \bullet^{-}$. Superoxide free-radical is also generated by phagocytic cells in response to microbial infections, allowing them to kill some of the bacterial strains they engulf. About $1 \%$ to $3 \%$ of the oxygen consumed by aerobic organisms generates $\mathrm{O}_{2}$. (Halliwell, 1992).

Lipid peroxidation, as a consequence of oxidative stress, can cause damage to cell membranes directly by altering membrane fluidity, permeability or integrity, or can attack DNA, carbohydrate and protein, and other molecules through self-perpetuating chain reactions and toxic by-products. Lipid peroxides can form cyclic peroxides, which can decompose to highly cytotoxic products such as aldehydes and alkoxyl radicals. These compounds react aggressively with living tissue and can disrupt cell membrane structure and diffuse from the lipid membrane and damage other cells. These cellular disruptions can lead to changes in permeability, viscosity, secreting activity, and enzymatic inactivation. These processes are discussed as pathobiochemical mechanisms involved in the initiation or progression phase of various diseases (Wiseman \& Halliwell, 1996). Coronary heart disease, carcinogenesis, cataract and age-related macular degeneration, neuronal diseases, neuro-muscular diseases, and a large number of other important diseases, such as Parkinson's disease and Alzheimer's disease, have been related directly or indirectly with oxidative stress (Diplock et al., 1998). In addition, during the past decade, several lines of 
evidence have convinced scientists that oxidative stress and ROS play an important role in aging (Beckman \& Ames, 1998). The ROS theory of aging suggest that aging is caused by the deleterious effects of accumulated free radicals throughout the life span (Cheeseman \& Slater, 1993).

Because most people view oxidative stress negatively, and the added stipulation that oxidative stress causes damage, it is important to differentiate good from bad oxidative stress. In some situations, oxidative stress can benefit the body by generating oxidants that help fight infections by killing or inactivating microorganisms or other non-live aggressors. The respiratory burst during inflammation, or the participation of ROS in the biosynthesis of some biologically active molecules such as eicosanoids (e.g prostaglandins), are examples of beneficial effects derived from cellularcontrolled ROS-generation (Halliwell, 1994). Figure 2 shows the concept of oxidative stress, and figure 3 summarizes ROS formation and aggression, and the main consequences to the human body.

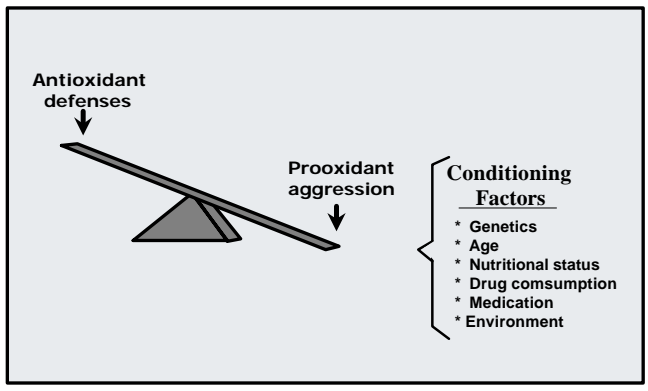

Figure 2

The concept of oxidative stress.

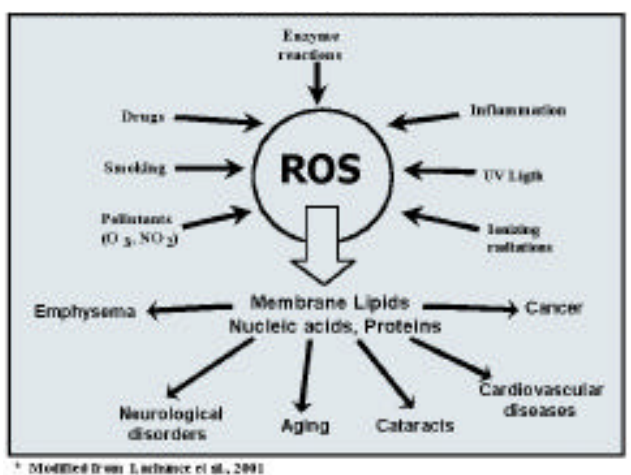

Figure 3

Reactive oxygen species (Ros): formation and aggression, and the main consequences to the human body*.

\section{ANTIOXIDANT DEFENSES AGAINST OXIDATIVE STRESS}

ROS-induced oxidative stress is rigorously controlled by multiple defensive lines which include enzymatic and non enzymatic scavengers and quenchers. These defenses either stop the free radical chain reaction or divert the free radical to a less deleterious target. Enzymes involved in ROS-induced oxidative stress defense are three groups of metal-binding proteins. The first comprises the superoxide dismutases (SOD), which scavenge $\mathrm{O}_{2} \cdot{ }^{-}$at the mitochondria (Mn-dependent SOD), nucleus and cytoplasm (Cu/Zn-dependent SOD). The second group are catalases (CAT) which are Fe-containing enzymes that remove $\mathrm{H}_{2} \mathrm{O}_{2}$ and are found in the peroxisomes in most tissues. They probably serve to remove peroxide generated by peroxisomal oxidase enzymes. The third are glutathione peroxidases (GSH-Px), which are the major enzymes that remove hydrogen peroxide generated by SOD in cytosol and mitochondria by oxidizing the tripeptide glutathione (GSH) into its oxidized form (GSSG) (Halliwell \& Gutteridge, 1986). Several subtypes of GSH-Px are selenium-dependent (Se)-dependent, i.e. $\mathrm{Se}$ is essential for catalytic function (Levander \& Burk, 1996) and at least four isoforms of the enzyme exist. They differ both in their tissue distribution and in their sensitivity to Se depletion (Arthur et al., 1996). Selenoprotein $P$ is another Se-containing protein suggested to be involved in protection against oxidative stress (Burk, 1990). The protein is made in the liver and secreted in the plasma where it works as a free-radical trapping molecule or as a selenium transport protein (Burk \& Hill, 1992).

The antioxidant enzymes are complemented by small-molecule antioxidants, some of which are derived exclusively from the diet and are vitamins. Major non-enzymatic defenses include GSH by itself, the tocopherols, carotenoids, and ascorbic acid, as well as free metal heme-binding proteins. Intracellular concentrations of these compounds can be substantial, i.e., in the millimolar range both for ascorbate and GSH (Halliwell, 1999). The mechanisms by which these antioxidants act at the molecular and cellular level include roles in gene expression and regulation, apoptosis, and signal transduction. Thus, these antioxidant molecules are involved in fundamental metabolic and homeostatic processes (Elsayed, 2001). Indirect antioxidant functions are mediated by enzymes that restore endogenous antioxidant levels, e.g. GSH levels are replenished on reduction of GSSG by the enzyme glutathione reductase. Because these defense systems are not $100 \%$ effective, the human body has also developed enzyme systems to repair the damage that ROS inflicts on DNA, RNA, and proteins (Winrow et al., 1993). Antioxidant defense systems have evolved to defend the body against 


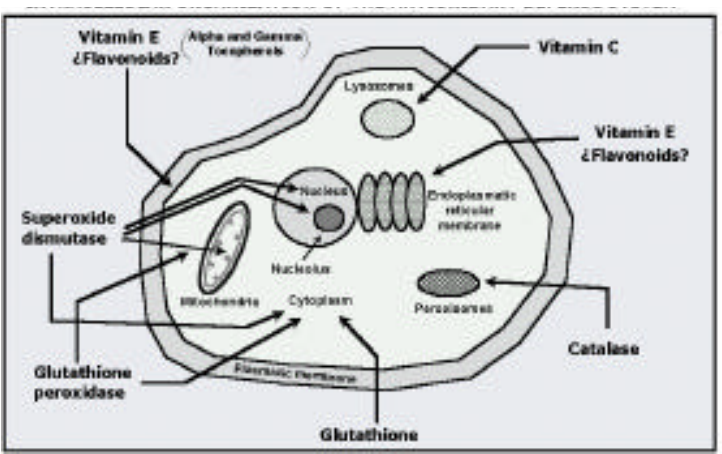

Figure 4

Intracellular organization of the antioxidant defense system.

ROS but might become overwhelmed during periods of chronic oxidative stress. The balance between ROS generation and antioxidant defenses may be a crucial force in chronic disease prevention (Machlin \& Bendich, 1987). It becomes apparent that an imbalance between protection against ROS and their generation can be associated with the pathogenesis of a wide variety of chronic diseases as discussed earlier. Figure 4 shows the intracellular organization of the antioxidant defense system.

\section{NUTRITIONAL PREVENTION OF OXIDATIVE STRESS: THE ROLE OF FUNCTIONAL FOODS}

Synthetic antioxidants added to foods that we consume, such as edible oils, margarine, mayonnaise, sausages, candies, snacks, etc., must be metabolized to be transformed from lipid-soluble substances to less lipid-soluble or mostly to water-soluble metabolites. These processes, that occur mainly at the liver, include structural modifications of synthetic antioxidants through the microsomal oxygenase pathway to inactivate them (phase I metabolism); the GSH conjugation pathways in which the tripeptide reacts with antioxidant metabolites at electrophilic sites; and the glucuronide or sulfate conjugation pathways that produce more highly soluble excretory products (phase II metabolism) (Rogers, 1991). These chemical modifications produce water-soluble conjugated metabolites that can be excreted via the urine. This is the metabolic fate of phenolic substances such as the antioxidants BHA, BHT, PG or TBHQ. However for natural antioxidants another metabolic routes may be possible, such as deposition in different tissues in preference to metabolism by the microsomal oxygenase pathway. This is the case for tocopherols, ascorbic acid, flavonoids, and natural polyphenols, which not only preserve food stability and composition, but also may exert their antioxidant action at the extracellular and/or intracellular level. This protective action may reinforce the activity of the endogenous antioxidant systems (Lachance et al., 2001)

Our endogenous antioxidant defenses are inadequate to prevent oxidative damage completely, therefore dietary supplementation with natural antioxidants sounds attractive because it offers a simple method of supplying supplementary protection to the antioxidant status of the organism. In addition, dietary supplements have advantages, such as ease of administration and acceptability by the subjects, constituting a dynamic interaction between environment and nutrition. Functional foods may comprise this supplementation (Hardy, 2000). The term functional food, which originates in Japan in the 1980s, refers to processed foods containing ingredients that aid specific bodily functions in addition to being nutritious (Harris, 2000). Most recently the definition has been extended to 'any food or ingredient that has a positive impact on an individual health, physical performance, or state of mind, in addition to its nutritive value' (Hardy, 2000). Today, functional foods are receiving substantial attention and represent one of the fastest growing segments of the world food industry (Milner, 2000). Therefore in addition to consumption of foods containing natural antioxidants, such as fruits, oilseeds, or other vegetables, consumption of processed foods supplemented with natural antioxidants such as tocopherols, ascorbic acid, rosemary extracts, flavonoids, lycopene, and others, may provide the desired antioxidant status (Hasler, 1998). These natural products may help to prevent early development of diseases where oxidative stress is a major or a derived component of the pathology, such as cardiovascular diseases, some cancers, neurological diseases, etc, allowing individuals better health and quality of life, mainly during senescence. Highly consumed foods, such as dairy products, bread, juices and beverages, meats, processed vegetables, etc, can be transformed into more healthy foods by the addition of natural antioxidants. However, determining the optimal intake 


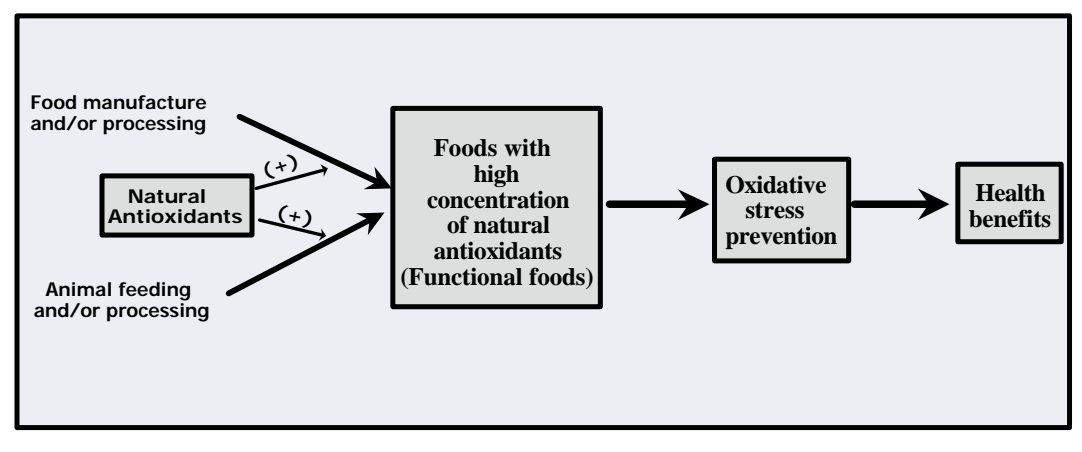

Figure 5

Natural antioxidants, functional foods, and health benefits.

of natural antioxidants through supplementation by functional foods is one of the greatest challenges in the nutrition and in the ROS chemistry and physiology field to day. Nutritionists, biochemists, food chemists, and food engineers, are involved in defining new natural antioxidants of high potency, low toxicity, and good solubility properties in aqueous or organic phases to develop new natural antioxidant- containing functional foods. Natural antioxidants can be defined as 'natural preservers of food quality and health'. Figure 5 summarizes the concept of natural antioxidants-containing functional foods and the health benefits associated.

\section{ACKNOWLEDGMENTS}

The work of the authors has been supported by FONDECYT, FONDEF, Ordesa SA (Spain) and by Alltech Inc (USA).

\section{REFERENCES}

Allen, R. G., and Tresini, M. (2000).-"Oxidative stress and gene regulation".- Free Rad. Biol. Med. 28, 463-499.

Aruoma, O. I. (1997).-"Extracts as antioxidant prophylactic agents"- INFORM 8, 1236-1242.

Arthur, J. R., Bermano, G., Mitchell, J. H and Hesketh, J. E. (1996).-"Regulation of selenoprotein gene expression and thyroid hormone metabolism".- Trans. Biochem. Soc. 24, 384-388.

Azzi, A., Aratri, E. and Boscoboinik, D. (1998).-“ Molecular basis of alpha-tocopherol control of smooth muscle cell proliferation".- Biofactors 7, 3-9.

Babior, B. M., and Woodman, R. C. (1990).-"Chronic granulomatous disease".- Semin. Hematol. 27, 247-259.

Beckman, K. B., and Ames, B. (1998).-"The free radical theory of aging matures".- Physiol. Rev. 78, 547-581.

Benzie, I. F. (1996).-"Lipid peroxidation: a review of causes, consequences, measurement, and dietary influences".- Int. J. Food Sci. Nutr. 46, 233-261.

Bieri, J. G. (1984).-"Sources and consumption of antioxidants in the diet".- J. Am. Oil Chem. Soc. 61, 1917-1918.

Bravo, L. (1998).-"Polyphenols: chemistry, dietary sources, metabolism and nutritional significance".- Nutr. Rev. 56, 317-333.
Bredt, D. S. (1999).-"Endogenous nitric oxide synthesis: biological functions and pathophysiology".- Free Rad. Res. 31, 577-596.

Burk, R. F. (1990).-"Protection against free radical injury by selenoenzymes".- Pharmacol. Ther. 45, 383-385.

Burk, R. F., and Hill, K. E. (1992).-"Some properties of selenoprotein P".- Biol. Trace Elem. Res. 33, 151-153.

Burton, G. W., and Ingold, K. U. (1984).-"Beta-carotene: an unusual type of lipid antioxidant".- Science 224, 569-573.

Carr, A., and Frei, B. (1999).-"Does vitamin C acts as a pro-oxidant under physiological conditions?".- FASEB J. 13, 1007-1024.

Cheeseman, K. H., and Slater, T. F. (1993)."“An introduction to free radical biochemistry".- Br. Med. Bull. 49, 481-493.

Chen, Q., Shi, H., and Ho, C. T. (1992).-"Effects of Rosemary extracts and major constituents on lipid oxidation and soybean lipoxygenase activity".- J. Am. Oil Chem. Soc. 69, 999-1002.

Clinton, S. K. (1998).-“ Lycopene: chemistry, biology, and implications for human health and disease".- Nutr. Rev. $56,35-51$.

Cook, N. C., and Samman, S. (1996).-"FlavonoidsChemistry, metabolism, cardioprotective effects, and dietary sources".- Nutr. Biochem. 7, 66-76.

Diplock, A. T. (1997).-" Will the "good fairies" please prove to us that vitamin $E$ lessen human degenerative diseases?".- Free Rad. Res. 27, 511-532.

Diplock, A. T., Charleaux, J. L., Crozier-Willi, G., Kok, F. J., Rice-Evans, C., Roberfroid, M., Stahl, W., and Viña-Ribes, J (1998).-"Functional food science and defense against reactive oxidative species".- $B r . J$. Nutr. 80 (suppl), S77-S112.

Dorko, C. (1994).-"Antioxidants used in foods".- Food Technol. 4, 33.

Dreosti, I. E. (2000).-"Antioxidant polyphenol in tea, cocoa, and wine".- Nutrition 16: 692-696.

Dzanis, D. (1991).-"Safety of ethoxyquin in dog foods".- J. Nutr. 121, S163-S164.

Elsayed, N. M. (2001).-"Antioxidants mobilization in response to oxidative stress: a dynamic environmental- nutritional interaction".- Nutrition 17, 828-834.

Evans, P., and Halliwell, B. (2001).-"Micronutrients: oxidant/ antioxidant status".- Brit. J. Nutr. 85, Suppl, S627-S74.

Gerster, H. (1997).-“ The potential role of lycopene for human health".- J. Am. Coll. Nutr. 16, 109-126. 
Halliwell, B. (1992).-"Free radicals, antioxidants, and human disease: curiosity, cause, or consequence?".Lancet 344, 721-724.

Halliwell, B. (1994).-"Free radicals and antioxidants: a personal view".- Nutr. Rev. 52, 253-265.

Halliwell, B. (1999).-"Establishing the significance and optimal intake of dietary antioxidants: the biomarker concept".- Nutr. Rev. 57, 104-108.

Halliwell, B., and Gutteridge, J. M. (1986).-"Oxygen free radicals and iron in relation to biology and medicine: some problems and concepts"-- Arch. Biochem. Biophys. 246, 501-514.

Hardy, G. (2000).-"Nutraceuticals and functional foods: introduction and meaning".- Nutrition 16, 688-697.

Harris, C. (2000).-"Meat products are perfect as functional foods".- Meat Processing. Jan/Feb. p.19.

Hasler, C. (1998).-"Functional foods: their role in disease prevention and health promotion".- Food Technol. 52, 63-70.

Havsteen, B. (1983).-"Flavonoids, a class of natural products of high pharmacological potency".- Biochem. Pharmacol. 32, 1141-1148.

Herrera, B., Alvarez, A. M., and Sanchez, A. (2001).-"Reactive oxygen species (ROS) mediate the mitochondrial-dependent apoptosis induced by transforming growth factor (beta) in fetal hepatocytes".FASEB J.15,741-751.

Jessup, W., Rankin, S., De Whalley, C., Hoult, R., Scott, J., and Leake, D. (1990).-"Alpha-tocopherol consumption during low-density-lipoprotein oxidation".- Biochem. $J$ 265, 399-405

Lachance, P. A., Zeina, B. S., and Jeong W. S (2001).-"Antioxidants: an integrative approach".Nutrition 17: 835-838.

Levander, O. A., and Burk, R. F. (1996).-"Selenium. In: Present Knowledge in Nutrition. (Ziegler, E. E., and Filer, L. S., eds.)".- ILSI Press, Washington DC. P 320-330.

Levine, M., Conry-Cantinela, C., Wang, Y., Welch, R. W., Washko, P. W., Dhariwal, K. R.., Park, J. B., Lazarev, A., Graumlich, J, F., King, J., and Cantinela, L. R. (1996).-"Vitamin C pharmacokinetics in healthy volunteers: evidence for a recommended dietary allowance".- Proc. Natl. Acad. Sci., USA. 93, 3704-3709.

Machlin, L. J. (1991).-"Vitamin E. In: Handbook of Vitamins (L. J. Machlin, ed). Marcel Decker".- Inc. New York, pp 99-144.

Machlin, L. J., and Bendich, A. (1987)."“Free radical tissue damage: protective role of antioxidant nutrients".FASEB 1, 441-445

Madsen, H. L., and Bertelsen, G. (1995).-"Spices as antioxidants".- Trends Food Sci. Technol. 6: 271-277.

Meydani, M. (1995).-“Vitamin E".- Lancet 345, 170-175.

Milner, J. A. (2000).-"Functional foods: the US perspective".- Am. J. Clin. Nutr. 71, 1654S-1659S

Morel, D., and Lin, C. Y. (1996).-"Cellular biochemistry of oxysterols derived from the diet or oxidation in vivo". Nutr. Biochem. 7, 495-506.

Nieto, S., Garrido, A., Sanhueza, J., Loyola, L., Morales, G., Leighton, F., and Valenzuela, A. (1993)."Flavonoids as stabilizers of fish oil: an alternative to the use of synthetic antioxidants".- J. Am. Oil. Chem. Soc. 70: 773-778.

Niki, E., Tsuchiya, J., Tanimura, R., and Kamiya, Y (1982).-"Regeneration of vitamin $\mathrm{E}$ from alphachromanoxyl radical by glutathione and vitamin C".Chem. Lett. 27, 789-792.

Oldman, K., and Bowen, P. (1998).-"Oxidative stress in critical care: is antioxidant supplementation beneficial?".- J. Am. Diet. Assoc. 98, 1001-1008.
Pietta, P. G. (2000).-"Flavonoids as antioxidants".- J. Nat. Prod. 63, 1035-1042

Rao, A.V., and Agarwal, S. (1999).-"Role of lycopene as antioxidant carotenoid in prevention of chronic antioxidant carotenoid in prevention of

Rao, A. V., and Agarwal, S. (2000).-"Role of antioxidant lycopene in cancer and heart disease".- J. Am. Col. Nutr. 19, 563-569.

Richheimer, S. L., Bernart, M. W., King, G. A., Kent, M. C., and Bailey, D. T. (1996) .- "Antioxidant activity of lipid-soluble phenolic diterpenes from Rosemary".- J. Am. Oil Chem. Soc. 73, 507-514.

Robey, W., and Shermer, W. (1994)."-The damaging effects of oxidation".- Feed Mix. 2, 22-26.

Rogers, A. E. (1991).-"Diet and toxicity of chemicals".- J. Nutr. Biochem. 2: 579-593.

Sardesai, V. M. (1995).-"Role of antioxidants in health maintenance".- Nutr. Clin. Pract. 10, 19-25.

Schiller, H. J., Reilly, P. M.., and Bulkley, G. B. (1993).-"Antioxidant therapy".- Crit. Care Med. 21 (suppl): S92-S102.

Shahidi, F. (2000).-"Antioxidants in food and food antioxidants".- Nahrung 44, 158-163.

Sies, H. (1993).-"Strategies of antioxidant defense".- Eur. J. Biochem. 215, 213-219.

Skibola, C. F., and Smith, M. T. (2000).-"Potential health impacts of excessive flavonoid intake".- Free Rad. Biol. Med. 29, 375-383.

Smith, L. L., and Johnson, B. T. (1989).-"Biological activities of oxysterols".- Free Rad. Biol. Med. 7: 285-302.

Stahl, W., and Sies, H. (1996).-"Lycopene: a biologically mportant carotenoid for humans?".- Arch. Biochem. Biophys. 336: 1-9.

Thompson, D., and Moldeus, P. (1988).- Cytotoxicity of butylated hydroxyanisole and butylated hydroxy toluene in isolated rat hepatocytes".- Biochem. Pharmacol. 37, 2201-2207.

Thurman. J. E., and Mooradian, A. D. (1997).-"Vitamin E supplementation therapy in the elderly".- Drugs and Aging 11, 433-449.

Valenzuela, A., and Nieto, S. (1996).-"Synthetic and natural antioxidants: food quality protectors".- Grasas y natural antioxidants:

Valenzuela, A., Sanhueza, J., Alonso, P., Corbari, A., and Nieto, S. ( 2002).-"Inhibitory action of conventional food grade natural antioxidants and of natural antioxidants of new development on the thermal-induced oxidation of cholesterol".- Int. J. Food Sci. Nutr. (submitted).

Valenzuela, A., Sanhueza, J., and Nieto, S. $\left(2002^{\mathrm{a}}\right)^{-}$-" Thermal stability of some natural products with antioxidant activity".- J. Am. Oil Chem. Soc. (submitted).

Weber, P., Bendich, A., and Schalch, W. (1996).-“Vitamin C and human health - a review of recent data relevant to human requirements".- Int. J. Vitamin Nutr. Res. 66, 19-22.

Wiseman, H., and Halliwell, B. (1996).-" Damage tom DNA by reactive oxygen and nitrogen species: role of inflammatory disease and progression to cancer". Biochem J. 313, 17-29.

Winrow, V. R., Winyard, P. G., Morris, C. J., and Blake, D. R. (1993).-"Free radicals in inflammation: second messengers and mediators of tissue destruction".- $\mathrm{Br}$. Med. Bull. 49: 506-522. 